\title{
Der Schutz des pränatalen Lebens
}

Eine verfassungs-, völker- und gemeinschaftsrechtliche Statusbetrachtung an der Schwelle zum biomedizinischen Zeitalter

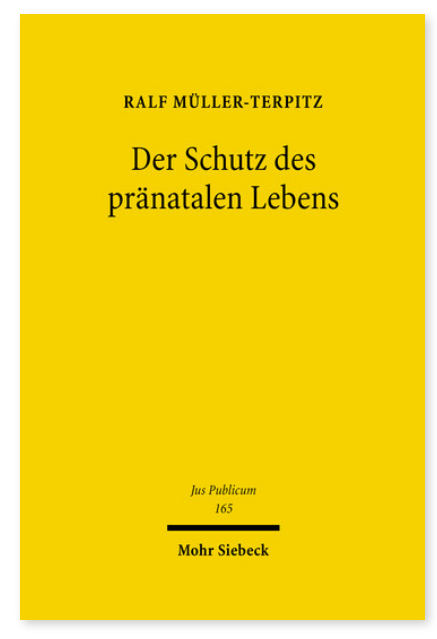

2007. XXV, 637 Seiten. JusPubl 165

ISBN 978-3-16-151246-9

DOI 10.1628/978-3-16-151246-9

eBook PDF 159,00€

ISBN 978-3-16-148914-3

Leinen $159,00 €$
Schon seit der Antike wird in der Philosophie, Theologie, Medizin, aber auch in der Rechtswissenschaft über den Status des pränatalen menschlichen Lebens gestritten. Durch jüngere biomedizinische Entwicklungen erhielt diese Debatte abermals kräftigen Auftrieb. Ralf Müller-Terpitz nimmt dies zum Anlaß, erneut der Frage nach dem rechtswissenschaftlichen Status des pränatalen Lebens im nationalen wie internationalen Recht nachzugehen. Er bezieht dabei die Statusdebatten anderer Fachdisziplinen (Naturwissenschaft, Ethik, Theologie) in seine Betrachtung mit ein und untersucht ihre Relevanz für den rechtswissenschaftlichen Diskurs. Seine Analyse beschränkt sich im übrigen nicht nur auf den verfassungsrechtlichen Status des pränatalen Lebens, sondern auch auf seine rechtliche Stellung im Völker- und Gemeinschaftsrecht. Für das nationale Verfassungsrecht kommt der Autor dabei zum Ergebnis, dass der Embryo - sei es in vivo oder in vitro - schon ab der Fertilisation oder einem vergleichbar frühen Entstehenszeitpunkt (Zellkerntransfer) grundrechtlichen Würde- und Lebensschutz genießt, der auch nicht unter Berufung auf sein noch frühes biologisches Entwicklungsstadium »prozesshaft abgestuft« werden darf. Im Völker- und Gemeinschaftsrecht wird das pränatale Leben zwar als schützenswertes Rechtsgut anerkannt; diese Rechtsordnungen gewähren ihm aber nur einen auf bestimmte Verwendungsverbote reduzierten »angemessenen « (relativen) Überlebensschutz. Abschließend erörtert der Autor die Frage, welche konkreten Schlussfolgerungen aus den Ergebnissen im Hinblick auf bestimmte biomedizinische Gefährdungstatbestände für das pränatale Leben zu ziehen sind.

Ralf Müller-Terpitz ist Inhaber des Lehrstuhls für Öffentliches Recht, Recht der Wirtschaftsregulierung und Medien an der Universität Mannheim.
Jetzt bestellen:

https://mohrsiebeck.com/buch/der-schutz-des-praenatalen-lebens-9783161512469?no_cache=1

order@mohrsiebeck.com

Telefon: +49 (0)7071-923-17

Telefax: +49(0)7071-51104 